\title{
Combining zmet and mec in study of user expectations for ideal catering customer service app
}

\author{
Ton Chaing ${ }^{1, \mathrm{a}}$, Hsin Rau', Wei Jung Shiang ${ }^{1}$ and Jon Luen Chiang ${ }^{2}$ \\ ${ }^{1}$ Department of Industrial and Systems Engineering, Chung Yuan Christian University, Taoyuan City 32023, Taiwan \\ ${ }^{2}$ Department of Electrical \& Electronic Engineering, City University London, Northampton Square, London EC1V OHB, \\ United Kingdom
}

\begin{abstract}
The designing and marketing models of general catering customer service APP are made from business owners needs or from commissioned design company's thoughts. The ZMET and MEC technique are used to understand the consumers more properly. Consumers usually will not purchase a product for just the physical content or functionality of the product but will do so because of other reasons, such as what the product presents socially, how it affects their emotions and more In this context, it is necessary to identify the meaning better. This research attempts to understand how customer satisfaction in the context of the catering industry could be understood better by identifying product and company attributes. The catering company can then develop a unique style of their own, so consumers can better understand the ethos of the company, their culture and style. According to consumers' experience, we conclude 5 user expectations of catering customer service APP, including Fans Evaluation, Online-to-Offline Consistency, Timeliness, Smart Order, and Customized Logistics. In this paper, the results of these information show that the user expectations of catering customer services APP will become the effective scientific reference and different patterns of cognitive communities.
\end{abstract}

\section{Introduction}

The purpose of this research is to use the ZMET technique along with MEC in order to draw mental diagrams per person and then analyze the mental diagrams in order to develop constructs defining the individual and make recommendations for the catering company. This research makes use of the MEC method and summarizes main constructs from the HVM diagrams that were developed for 12 interviewees. Five key factors are considered for the construct development which is that of Timeliness, Fans Evaluation, Smart Order, Customized Logistics and Online-to-Offline Consistency.

ZMET constructed for different target audiences can help establish the segment's consensus map. This way the marketing group will be able to determine the type of strategy needed to communicate with them. As the ZMET technique allows the audience to tap into their own ideas and develop pictures for just the concepts that they associated with the catering service experience, the researcher is hence able to understand the mental model behind the user opinion construction.

\footnotetext{
${ }^{a}$ Corresponding author : tchiang.0514@ttri.org.tw
} 
The MEC technique used with the ZEMT technique will be useful for understanding the cognitive hierarchies of consumers when it comes to product consumption. The Means end chain theory MEC has been defined in the research literature on consumer oriented food products as being a more relevant way to understand consumer satisfied designs $[1,2]$. Product consumption motives are better understood as the marketer and the product maker will be able to better understand 1) how product attributes are linked to the self-relevant consequences of consumption of the person, their personal life values, goals and more and 2) to identify the hierarchical cognitive structures which present the consumer's mind. This consumer cognitive structure hierarchy will be useful to evaluate and understand how consumers might assess alternative products, why they make a choice to buy a product and why they might choose to buy another product instead. The higher order reasoning constructs from the mental models created from ZMET image collections and the story telling processes are useful to understand salience of some criteria over others [3, 4]. The functional and the psychological consequences of the product and how it connects to meet the consumer goal or value are hence very significant in this study.

\subsection{Interview questions}

Some of the interview questions to be used are with respect to understanding why a certain image was chosen, why a certain image was chosen over another image, etc.

Interview question I: Why do you select this picture? What kind of feelings and thoughts about the image of catering industry customer service APPs is represented by your selecting this picture?

Interview question II: Would you like us to know what kind of actual benefits or psychological satisfaction this choice brings to you. Why is the choice or construct valuable to you? Is the value in this part concerned with your personal preference? How about the significance of this value to you?

The interview questions are only guidance, the story telling and the mental models are basically encouraged from the consumer end.

\section{Consensus and constructs}

The number of interviewee consensus with respect is for consumer experience on different constructs below the table 1 shown. The constructs on which there is maximum customer consensus is seen to be that of clean environment and brand reputation. The clean environment consensus indicates that customers connect a favorable experience with a catering company that can project the same. Brand reputation, such as that of the history of catering, the positive experiences that the customer has with the brand, the reach of brand, its marketing, its CSR activities are also considered to be high on the consensus.

Table 1. Consumers Experience of the Catering Services.

\begin{tabular}{|c|l|}
\hline $\begin{array}{l}\text { Number of } \\
\text { Interviewees based on } \\
\text { consensus on the } \\
\text { Catering Services }\end{array}$ & Consumers Experience \\
\hline 12 & Clean enviroment, Brand reputation \\
\hline 10 & Courteous and well trained staff, High rating \\
\hline 9 & Green packaging, Polite service, Arrangements, Brand exposure, Food freshness \\
\hline 8 & Food taste, Complaint feedback fast, Timely order, Food design \\
\hline 7 & Service concept, Service and Product presentation, Knowledge on food practices \\
\hline 5 & Unique presentation of food and related services, Discount, Lively ambience \\
\hline 4 & $\begin{array}{l}\text { Eagemess to serve, Assurance for customers on time and quality, Shared knowledge } \\
\text { on food sourcing, Fun service }\end{array}$ \\
\hline 3 & Timely execution, Overall satisfaction, Customer awareness, Fresh orders \\
\hline
\end{tabular}


Courteous well trained staffs, food taste, service concept, presentation of food, eagerness to service and more are listed under moderate consensus. This collection of data is interesting, as customers are seen to associate clean environment, staff, rating and brand reputation as being their highest expectations with respect to catering. In terms of timely execution, freshness of orders or assurance on time seems to be listed with low consensus. This is a paradox because the most basic elements that a consumer would look for in a catering service are that it should be timely and the products must be fresh, however highest consensus is for brand reputation. Now this need not exactly be a paradox. Brand reputation can be understood to be a more abstract construct or a complex construct. A brand would have good reputation only if the brand is seen to have fulfilled some of the basics such as that of clean and fresh food, timeliness in service and more. So the high consensus rate for constructs such as brand reputation only indicates that the consumers would have taken the most basic constructs as being default requirements for the catering service to fulfill.

\section{Experiment of HVM}
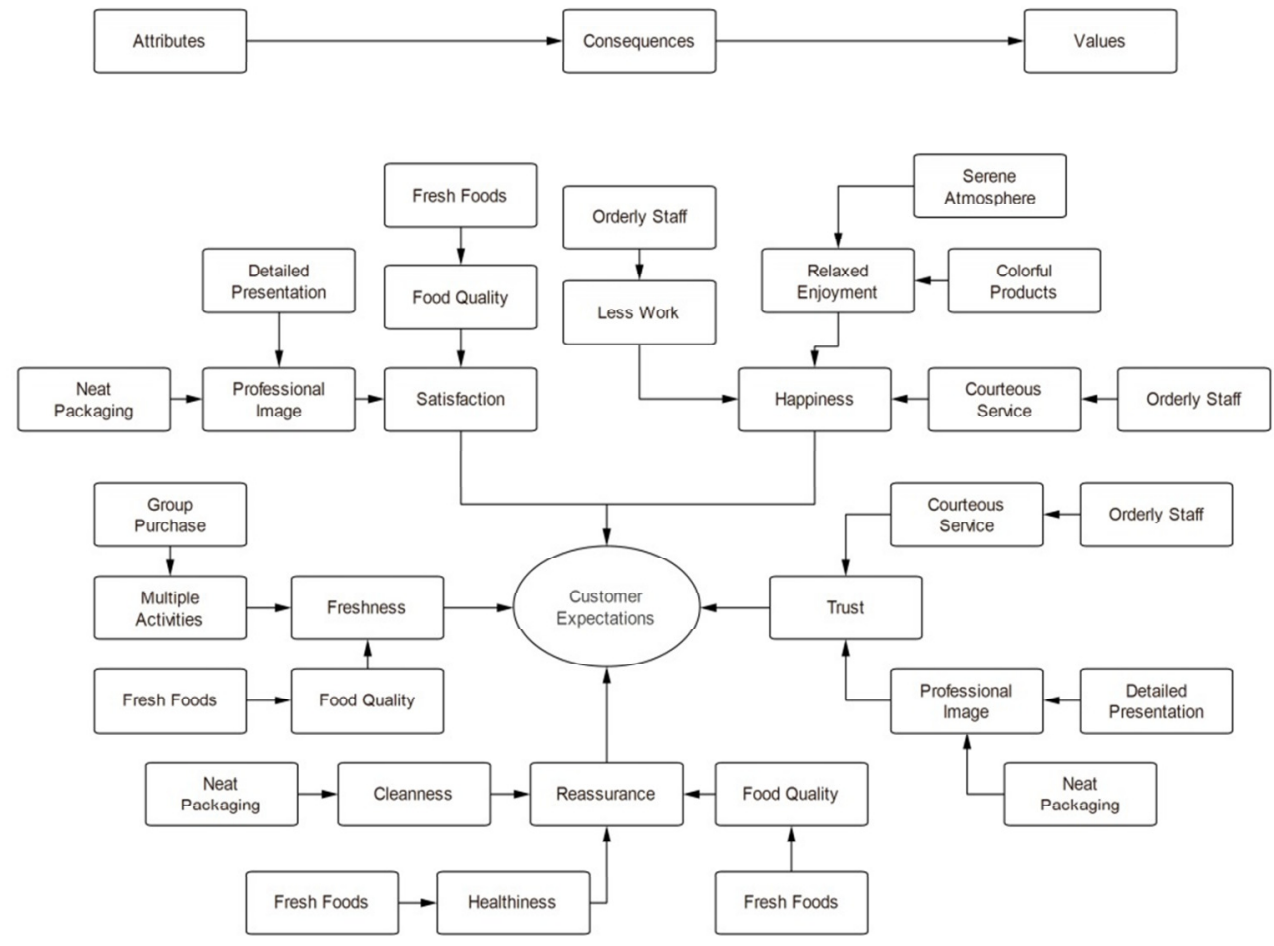

Figure 1. Model of HVM (Hierarchical value map).

The HVM graph has been constructed. The HVM graph is critical to understanding how the attributes, the consequences and the values are connected [5, 6]. Now as noticed in the case of Maslow's hierarchy, the physiological needs have to be satisfied first, so a person might have a need for say food and shelter. Before attaining a second level, the first level has to be satisfied. Now in the case of the figure 1 , there are concrete and abstract attributes and these have to be considered before their consequences could be understood. So in the catering services, neat packaging, fresh foods and more are some of the most basic elements. They have to be met irrespective of anything. Secondly, these attributes have consequences which are the more informative end compared to the meta data. These are functional and psychological implications and hence are one order up from just discussing about packaging. The quality of food would have a functional implication. And on the other hand, the way the food looks, its texture, its colour or its aroma would have a psychological implication. 
Now using these elements, in the figure 1, the value is understood. The value is at the meta level, where the data state for the app has crossed into the information stage. This is more of the higher end in the catering service, such as the management whose concerns are about value and adding value. Similarly, it can be said that the higher level value element of satisfaction and happiness is guaranteed because of courteous service. Where the service is courteous, then it automatically follows that the person requesting the services is satisfied, he is happier. On the other hand, where the courteous service is lacking, then the higher level values for the customer such as that of satisfaction and happiness is not achieved. In essence this is like a neural network where the firing of neurons at the consequences levels will trigger the value level and where consequences level is not triggered then there will be failure at the (customer) value level.

Marketing would now not look at the basic levels such as that of the constructs, attributes or the consequences, and instead tweaking for successful marketing is now being carried out at the values level. Further iterations in the creation of the graph will fill in any inconsistencies.

\section{Customers service App}

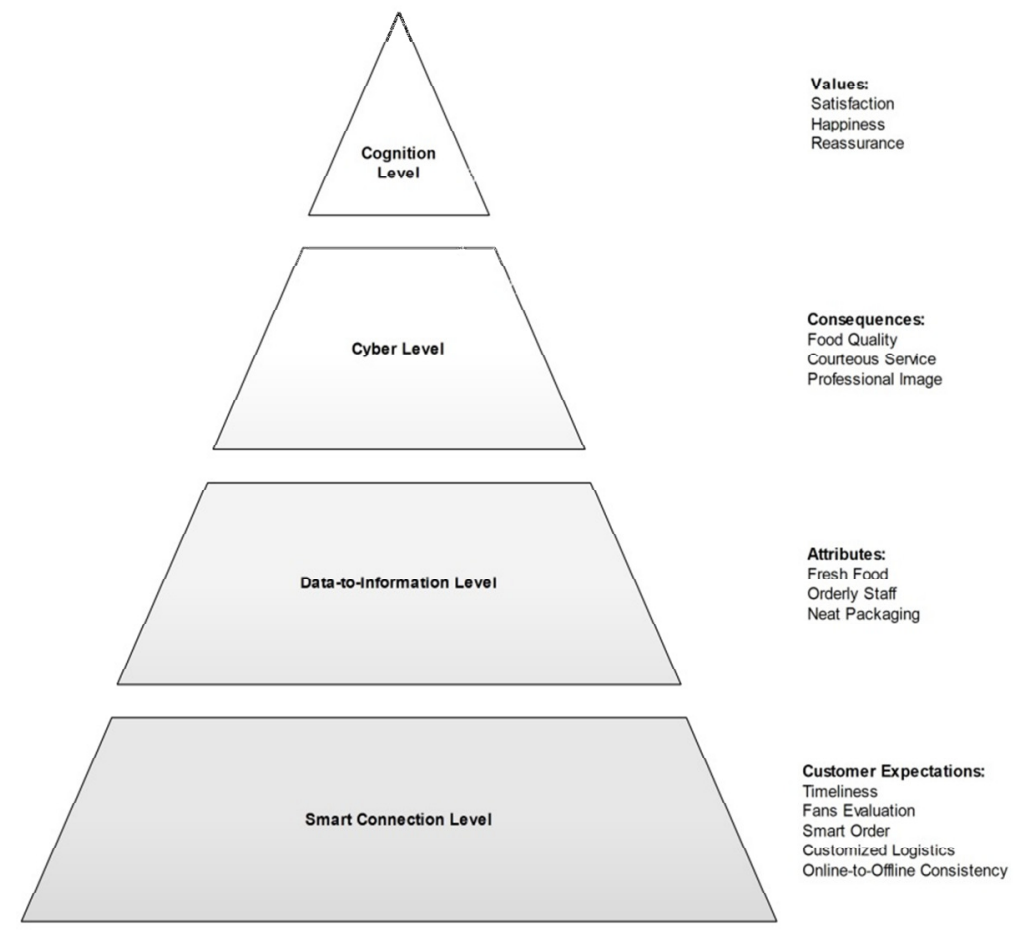

Figure 2. App value proposition process.

The theory of this figure is from Maslow Hierarchy. The Maslow hierarchy of needs or motivation proposed by Abraham Maslow and it has relevance in today management system [7]. It has paved a way to understand about the human psyche and helps in analysing about the people and their requirements. It basically helps in identification of the basic requirements of the people and provides a management style for the people. It also plays an important role in developmental psychology of the people. Maslow uses some the basic tenets of human motivations to develop a robust principle of people management. There are many hierarchical levels to Maslow, this has been divulged in detail in the following. Now similar tenets could be understood in the APP value proposition style.

The first level in the hierarchy is physiological needs. This is the basic requirements that are required for the humans to survive. It discusses in detail about the air, water and metabolic organic requirements of the humans. Apart from this, it also factors in the organic requirements of the human and basic 
principles of food and shelter. The second stage is the safety requirements of the people. It divulges about the safety requirements both from mental and physical safety. This is a natural security instinct of the people. There are many variables such as finance, personal security. Health and adverse impacts are considered in this analysis. The third hierarchical stage is the love and belonging stage of the people. When the basic tents are met, people aspire for the levels above them. They will want to form groups but at the same time want to affiliate with the people in the next level. This is a basic requirement of wanting to be accepted and valued by others. The people often engage in a profession or hobby to gain recognition. The people want to respect within their peer groups or society around them in order to be recognized.

The esteem levels, inferiority complexes are addressed in these levels. Once these basic tenets are achieved the next stage if the self-actualization state. In this stage, the person starts to perceive and focus on their exact needs and specifications. This is a basic human requirement of wanting to belong to a certain self-requirement that is beyond the scope of the tangible levels. The next level was prescribed by Maslow as people wanting to reach high levels of spirituality. Similar to the levels in Maslow's hierarchy, consider how there are different levels in the case of the app construction. At the base, the consumer oriented constructs, are present which needs to be satisfied for user. These are the basic constructs and similar to the physiological needs, nothing could be analysed further if these are not met. In the figure 2, it shows that these consumer constructs include the elements of timeliness, fans evaluation, smart order, customized logistics, and online-to-offline consistency. The second level is that of the attributes that include the data to information level offering at which point the raw data from the consumer end is already being transformed to information of meaning. At the cyber level, the storage of such information is construed such that at the cognition level the management would be able to understand the values breakdown.

Now there are many criticisms to this Maslow hierarchy of needs. It has been often contended that this is a blanketed approach in dealing with people and that each situation of the individuals is unique. Owing to this, there has been a general contention that this tool can be used to identify basic requirements of the people, and it should be altered to meet the requirements of the individuals in each subjective environment. Thus, this is a broad overview of the Maslow hierarchy that has been used in the office environment for effective people management and also in understanding of the basic psyche of the people.

\section{Key factors and recommendations for the catering industry}

\subsection{Timeliness}

Timeliness is a key aspect for the catering service. Some of the consumer participants that were selected only seemed to indicate that they did not choose pictures related to the time aspect only because it was not present in the image bank.

Customers associated service satisfaction with timeliness and consider the choice of brand as having a cause effect on timeliness as in some brands are mot time effective than others. Consumers expect consequences from the timeliness aspect. Some consumers have very strict schedules for the events they want to hire the catering service for and here they would like to see some of the common values identified for all participants in the form of reassurance. Reassurance is the service extended to the customer by means of sharing information on time aspects, information on what the customer could expect and how much time the customer might have to allocate catering services from the time of the order, the time within which a service could be cancelled and deposit returned to the customer etc.

Time based brand messages have to be included by the catering service to remind the customers of how much satisfaction they could have derived from the catering service in the past because of their being very time efficient. 


\subsection{Fans evaluation}

Fans evaluation plays a critical role in how the catering service might be perceived by other potential customers. Now there are some key values identified for the company in the form of reassurance, trust, satisfaction, freshness and happiness. Fans must be given the ability to rate each of these aspects or values for the catering services. In order to increases fan popularity for the catering service, the service must also ensure that they improve on these core elements. Some of these values can be improved on as a form of short term strategy and some of the others could be improved on as a form of long term strategy. For instance, in the context of reassurance, the short term strategy would be to consider how to incorporate freshness and satisfaction. Trust elements could be postponed but nevertheless should form a part of the long term strategy.

\subsection{Smart order}

Consider the case of the smart ordering system. A smart order system solves many problems for the consumers especially in the case of reducing the time they would take to make the orders. Customers would be able to place smart orders in a clearer way, which would also make the ordering experience very satisfactory in context. Some of the opinions of the customers seem to indicate that they would expect the catering service to be more of a homely one than a professional one. The use of a smart order system could lead to the experience becoming more professional, but care should be taken to ensure that it does not have the rigidity of the automatic systems that most businesses seem to prefer in current times. The smart order system should work such that the catering order placement will trigger the orders for the needed food sourcing, so the food sourcing would be kept as fresh as possible until the last minute. This is a good idea hence to satisfy the needed values of freshness and happiness that the customer participants required.

\subsection{Customized logistics}

In the interview-story telling process, it was identified that some customers wanted a very elite and professional service, some wanted a homelier service, some wanted a décor or environment that was more similar to a restaurant and others wanted ambience according to their needs at that time. Most of them had said that the service should be fun, and there were many requirements on the service staff, too.

In this context, customized logistics systems would be very useful. A customized logistics procedure is not a modification of an existing procedure but is more of an extension of the existing procedure. The customized logistics system will ensure that any areas of inconsistency or areas of interconnections between suppliers and the end product takers where there are lags would be addressed. This form of customization in logistics would make the brand more commendable.

\subsection{Online-to-Offline consistency}

Most times the offline presence of the company might not translate in online effects and vice versa. The promises of customer satisfaction made online, the objectives presented and more should be ensured. There should be consistency and only then the brand would be viewed with a little bit of stability. A catering customer service (online) app like the one below would serve to encapsulate the online to offline inconsistencies and hence would be better recommendation for the catering service company.

\section{Catering service APP}

The app creation is first initiated with a consistent study. A consistent study is a requirement, so as to understand whether the app can improve customer satisfaction [8]. In the figure 3, the primary issue 
that needs to be investigated is to understand the online-offline inconsistencies that are noticeable in customer feedback. Now based on the target market competitive profile and also the industry-market analysis, it would be necessary for the catering company to formulate an online marketing strategy that would be helpful for them. Recognition becomes an issue, as although the company being represented by a marketing strategy it might still not be recognized well. People searching in social media should know what they look for, so in the context of having both offline and online factors it would be necessary to maintain a consistency. Sometimes, this would mean adopting the same avatars or the same descriptions in marketing throughout, be it online or offline. For instance, in the case of the current situation, some of the attributes that were considered were that of freshness, happiness, satisfaction etc.

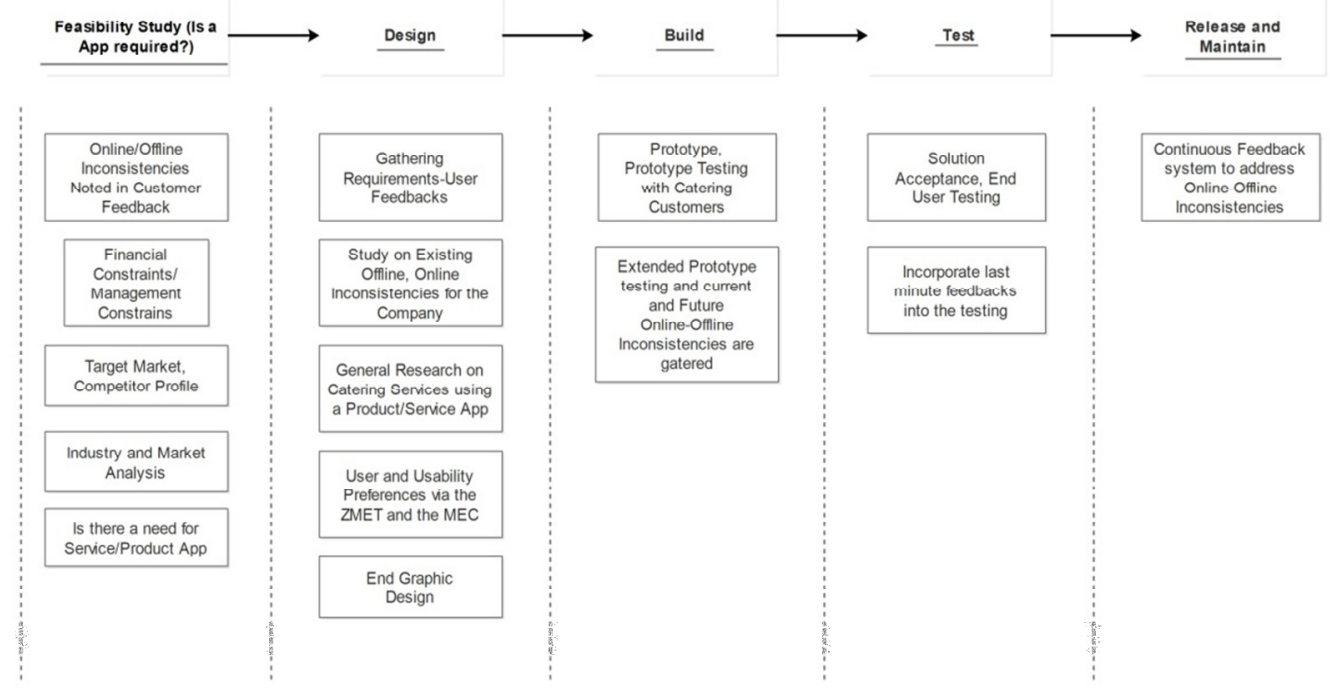

Figure 3. App requirements from design to release.

In developing a form of marketing, it would be necessary to consider each of these attributes is maintained consistently. The product presentation in the store such as that of catalogues which are used to present the form of catering products and services that are provided to the customer might look fresh or fun. But if the social media representation of these products and services do not match the freshness they offer, then this is an issue. Similarly, arguing for the case of adopting the overall tone of the profile, it is critical to remember that the person who searches for the catering company would also be looking it up by the overall profile. So there has to be consistency in creating social media profile to connect with the consumer. A counter argument that would be placed at this point is why a social media profile is needed in the first place, i.e. Is an app necessary? It is, given that more people are beginning use the internet to understand and connect with their brands.

People use multiple platforms in order to find the business that best suits them, they might end up using such platforms as that of messaging for finding their services, or they would use Instagram to look at the pictures of a catering service or they might end up looking at some of the social media talk on a company product and service etc. Now in the development of the app, one of the feasibility concerns that would be introduced is that of how the company is able to connect the different forms of messaging in ways that once again reflect consistency. A catering service cannot just afford to copy past the content that is present in one catering unit onto another. It would be necessary for the catering service to carefully understand the form of audience that would exist for the different messaging services and accordingly tailor make the content, the core essence of the content should however be similar. A consistent tone must be adopted even if specific tailoring has to be done. This will ensure that customers even if they switch different social media platform and search for something they would still be satisfied. Now by ensuring different social media can be connected to with the app, the catering service would be able to find a single point access for its services. It would be able to ensure 
that all the catering sub units (if there are any) are indeed connected across with just one app. Customers can leave feedbacks, study word of mouth comments and more on the app itself and be informed accordingly.

In feasibility, one of the main concerns as defined earlier is consistency. Consistency in online marketing is more challenges, because most of the social media and marketing media messages are created by the consumers themselves. The marketing media messages are created by the marketing group and then the media message is passed on through the app (as observed in this case), but this media message will not be sent out or passed word for word in the market. The consumer who reads the messages will interpret the marketing message in their own way. Based on how satisfactory they find the service from their personal experiences would be used by the consumer in order to make their own messages. In the context of marketing, this could mean that online marketing by means of the app would never be successful in consistency as is noted. However, to a certain extent the app can deliver consistency and hence deliver satisfaction for the consumer as well.

In the development of the app, prototype testing and end user testing is done, along with the incorporation of a continuous development feedback system. The continuous development feedback system is critical as it ensures that the customers' issues with inconsistency are collected. These issues are then considered as future improvement steps for the app and changes are made accordingly. The consistency check would either be done by working directly with the consumer in the form of feedback or focus groups. This form of continuous feedback system furthermore ensures customer satisfaction as the customer believes they are involved in the system.

\section{Discussions}

\subsection{Maslow Hierarchy of Needs}

The main differences and similarities between Maslow's hierarchy of needs theory and Alderfer's need theory are:

The biggest difference between them is that according to Maslow's hierarchy of needs theory, high level needs cannot become incentive factors before low level needs are satisfied. However, according to binary factor theory, hygiene factors and incentive factors can maintain or motivate employees at the same time.

The main differences and similarities between Maslow's hierarchy of needs theory and the Self-determination theory (SDT) are:

STD: The key point focuses on the motivations of personal stimulation and self-determination; in accordance with Maslow's hierarchy of needs, the all behaviors of humans are caused by their needs or demands.

\subsection{Smart Connection Level}

The ZMET, MEC and HVM in the research are discussions on the demands of network APP consumers, and they are launched to markets after APP value-adding process design is conducted. The most fundamental conditions must be satisfied on the basis of network technology development architecture. In order to reach consumer value HVM, the foundation of APP value-adding shall start with the mart connection level approach of network technology.

\subsection{Online-to-Offline consistency}

The most fundamental conditions must be satisfied on the basis of network technology development architecture so as to reach the other four factors of consumer values (Fans Evaluation, Timeliness, Smart order, and Customized Logistics). As a result, the APP value-adding process shall start with the Online-to-Offline Consistency of network technology. 


\section{Conclusions}

The research work attempted to understand by means of the ZMET and the MEC technique how a catering service brand is perceived by the consumers using the catering service (or potential new consumers for the catering service) [9]. Using the ZMET data in the form of image selection from the consumers was obtained, and also an interview for story telling was conducted. Based on the data, different key constructs and their numbers of consensus were identified.

The MEC technique application enabled the researcher to identify attributes, values and consequences $[10,11]$. The use of this form of technique led to a more holistic understanding of how the consumer will perceive the brand. Based on the data collected, recommendations are made based on the values of reassurance, trust, satisfaction, freshness and happiness. Some of the conclusive units based on which the service industry could hence improve are that of timeliness, fans evaluation, smart order, customized logistics, and online to offline consistency.

A limitation of this research is that in the usual ZMET technique, customers would be allowed to collect their own pictures. The customers (participants) are hence the drivers of the research and not the researchers. However, in this research study, because of the time constraints an image bank was created and the participants choose images from the bank instead. It is recommended that in future research, the participants will be given complete freedom to choose their own images. This will help in unearthing newer issues better.

Using the Maslow hierarchy style modelling helps understand a more abstracted representation of things, it would be necessary for the app developer to go in depth in order to meet customer satisfaction requirements.

Hence, the app can have a more personalized feedback system where the app would be able to connect with each of the customer and then make use of the feedback to set up a batch which would be rolled out in the next patch on the app.

\section{Acknowledgement}

In short, since the professional skillful distinction of ZMET and MEC focuses on the discussion about perceptual cognition, the conclusion of discussions about the ideal catering industry customer service image shall also be dominated by the connotations of APP expected by consumers/the sensory and value cognitive dimensions presented by the APP. However, it is suggested that in-depth discussions about functional demands for smart phones like such information system dimensions as the intimacy (downloading speed, easy to search, etc.) of service (response speed, safety and convenience) website (Screen Shot) design could be strengthened in the follow-up research. Besides, the main difficulty in the research method of ZMET lies in the elicitation of main constructs, so constantly improving the elicitation technology and knowledge and making the conclusion more simple and precise shall be the focus worthy of the further research next. Recently, some researchers have started trying to lead this research method to the collection of film studies or film/cartoon development, which will make the effective information obtained during research more abundant; however, with the increasing of the complexity of the based information, it will be more and more difficult in eliciting and mastering the cognition via this method, which shall also be considered in the subsequent research.

\section{References}

1. J.A. Gutman, Means-end chain model based on consumer categorization processes, J. mark., 46, 60-72 (1982)

2. J.C. Olson and T.J. Reynolds, The means-end approach to understanding consumer decision making. In J.C. Olson, \& T.J. Reynolds (Eds.), Understanding consumer decision making: the means-end approach to marketing and advertising strategy, Mahwah, NJ: Erlbaum, 3-20 (2001)

3. K.G. Grunert and C. Valli, Designer-made meat and dairy products: consumer-led product development, Livestock Production Science, 72, 83-98 (2001) 
4. K.G. Grunert, E. Sørensen, L.B. Johansen, and N.A. Nielsen, Analysing food choice from a means-end perspective, European Advances in Consumer Research, 2, 366-371 (1995)

5. D.A. Costa, M. Dekker, and W.M.F. Jongen, An overview of means-end theory: potential application in consumer-oriented food product design, Trends food sci. technol., 15 (7), 403-415 (2004)

6. A.L. Biel, Brand Equity \& Advertising: Advertising's Role in Building Strong Brands, Converting Image Into Equity, 67-82 (1993)

7. M.A. Wahba and L.G. Bridwell, Maslow reconsidered: a review of research on the need hierarchy theory, Organ. Behav. Hum. Perform., 15, 212-240 (1976)

8. D. Dobni and G. George Zinkham, In search of brand image: a foundation analysis, in advances in consumer research, eds. Marvin E. Goldberg, Gerald Gorn and Richard W. Pollay. Provo, UT: Association for Consumer Research, 17,100-119 (1990)

9. G.L. Christensen and J.C. Olson, Mapping consumers mental models with ZMET, Psychology \& Marketing, 19, 477-502 (2002)

10. E. Eakin, Penetrating the Mind by Metaphor, The York Times, February 23, B9 (2000)

11. G. Zaltman and L.J. Schuck, Seeing through the Customer's Eyes with Computer Imaging, In Sense \& respond: capturing value in the network era, edited by Stephen P. Bradley and Richard L. Nolan. Harvard Business School Press, Boston, MA (1998)

12. G. Zaltman, Consumer research: take a hike, Journal of Consumer Research, 26,423-428 (2000)

13. G. Zaltman, Metaphorically speaking, Marketing Research, 8, 13-20 (1996)

14. G. Zaltman, Rethinking market research: Putting people back in, J. Mark. Res., 34, 424-437 (1997)

15. G. Zaltman, How Customers Think: Essential Insights into the Mind of the Market, Harvard Business School Press, Boston, MA (2003)

16. J.J. Collier and C. Malcolm, Visual Anthropology: Photography as a Research Method, Revised and expanded edition. Albuquerque, NM: University of New Mexico Press (1986)

17. J. Gutman, Exploring the nature of linkages between consequences and values, Journal of Business Research, 22, 143-148 (1991)

18. S.M. Kosslyn and O. Koenig, Wet Mind: The New Cognitive Neuroscience, NY: The Free Press (1992)

19. M. Blaxton, Brand Equity \& Advertising: Advertising's Role in Building Strong Brands, Beyond Brand Personality: Building Brand Relationships, 113 (1992)

20. M. De Reuver, H. Bowman, N. Heerschap, and H. Verkasalo, Smartphone measurement: do people use mobile applications as they say they do? 2012 International Conference on Mobile Business, Paper 2 (2012) 